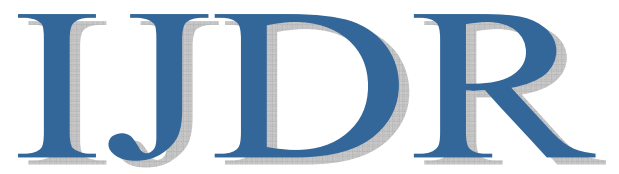

International Journal of Development Research

Vol. 10, Issue, 05, pp. 36185-36192, May, 2020

https://doi.org/10.37118/ijdr.18961.05.2020

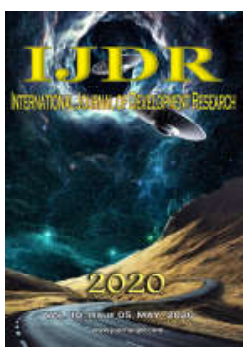

\title{
ANALYSIS OF THE PLANNING OF THE FLOW OF MILITARY INPUTS AND SUPPLIES BY THE AMAZONIAN RIVER MODAL
}

\section{${ }^{1}$ Lucas Vieira Gonçalves, ${ }^{1}$ Mauro Cesar Aparício de Souza, ${ }^{1}$ Alexandra Priscilla Tregue Costa, ${ }^{2}$ Marden Eufrasio dos Santos and ${ }^{* 2}$ David Barbosa de Alencar}

\author{
${ }^{1}$ Academic Department, University Center FAMETRO, Amazon-Brazil \\ ${ }^{2}$ Institute of Technology and Education Galileo of Amazon (ITEGAM), Brazil
}

\author{
ARTICLE INFO \\ Article History: \\ Received $17^{\text {th }}$ February, 2020 \\ Received in revised form \\ $03^{\text {rd }}$ March, 2020 \\ Accepted $20^{\text {th }}$ April, 2020 \\ Published online $30^{\text {th }}$ May, 2020 \\ Key Words: \\ Logistic Planning; River Transport; \\ Logistics in the Amazon. \\ *Corresponding author: \\ David Barbosa de Alencar,
}

\begin{abstract}
Logistics is understood in the art of engineering, planning, storing, moving, distributing and transporting in different axes, either internally or externally to organizations in the calculated time and in the correct place in a logical way, as well as the meaning of this word in its Greek origin. In the spectrum of this arrangement, in the boundaries of the nation, the Amazon region rises, whose geographical peculiarity sharpens the need for innovation and malleability of the logistical characteristics employed, among which the massive use of the waterway transport modal as well as for its fluency stands out. module, it is necessary to prepare related areas concurrently with the entry, development and disposal of goods. This content aims to demonstrate the configuration of the planning and execution of Amazonian logistics with a focus on the movement of material by hydrographic routes, both in the manufacture of inputs and the flow of goods in military artifacts in order to seek in these procedures an evolution in the concept of the transport logistics function.
\end{abstract}

Copyright (C) 2020, Lucas Vieira Gonçalves et al.. This is an open access article distributed under the Creative Commons Attribution License, which permits unrestricted use, distribution, and reproduction in any medium, provided the original work is properly cited.

Citation: Lucas Vieira Gonçalves, Mauro Cesar Aparício de Souza, Alexandra Priscilla Tregue Costa, Marden Eufrasio dos Santos and David Barbosa de Alencar. "Analysis of the planning of the flow of military inputs and supplies by the amazonian river modal", International Journal of Development Research, 10, (05), 36185-36192.

\section{INTRODUCTION}

Logística ou Gestão Logística como a parte da Cadeia de Abastecimento é a parcela responsável por planejar toda a execução do processo, implementar e controlar o eficiente e eficaz fluxo direto e inverso e as operações de armazenagem de bens, serviços e informação relacionada entre o ponto de origem e o ponto de consumo de forma a ir ao encontro dos requisitos/necessidades dos clientes para a compra ou venda de um determinado produto ou serviço [1]. A arte logística deve ser concebida para atender às operações de amplo espectro, em situações de guerra e não guerra, com uma estrutura capaz de evoluir de uma situação de paz para a de guerra/conflito armado. Para tanto, sua organização será pautada pela flexibilidade, adaptabilidade, modularidade, elasticidade e sustentabilidade passando com este contexto atender a demandas diversas que são suscetíveis a mudanças bruscas e de ordem [2]. Nesta seara, considerando as afirmativas citadas, a pauta a ser elucidada nas duas definições acima é a importância da logística para os processos naturais da humanidade de qualquer ordem e dentro de ambientes mais inóspitos e precários, onde afunilam-se as possibilidades, os transportes, os meios e as dificuldades saltam de forma significativa, a necessidade da grande assistência logística é fundamental, considerando estes fatores destaca-se dentro do cenário brasileiro o ambiente Amazônico, pela peculiaridade de seus referenciais de subsistência. Os diversos eixos fluviais do estado do amazonas representam e são concomitantes as vias do restante da nação, isso reflete o significado da grande parcela dos municípios do estado possuírem nos rios a sua única e ou principal alternativa de interligação com outras cidades. A logística e o transporte são imprescindíveis no desenvolvimento social e econômico de qualquer país e em qualquer localidade, visto que há neste espectro uma estreita e direta relação de reciprocidade entre transportes, aquisições armazenagem, progresso e desenvolvimento econômico [3]. A peculiaridade descrita acima nos remete ao estudo da peculiaridade da região amazônica contudo enfatizando a observância de dados estatísticos coletados na própria região para embasamento e verificação da eficiência e eficácia desta 
versão de modal de transportes que demonstra atualmente ser a vertente mais utilizada nesta região. A finalidade de obter os dados referentes a toda essa dimensão logística na Amazônia esbarra na pouca referência bibliográfica sobre esta pauta, tornando a obra mais um suporte teórico para próximos referenciais acerca do tema. Congruente, o objetivo da demonstração desta obra é remeter as diferenças e possibilitar aos leitores a capacidade de iniciar a comparação entre o planejamento realizado para execução de um transporte de insumos civis e militares pelo modal fluvial amazônico de uma unidade militar referência na atuação na Amazônia e àquele utilizado por sociedades civis de mesma região.

\section{FUNDAMENTAÇÃO TEÓRICA}

A formulação deste estudo baseia-se basicamente na função logística transporte com ênfase na região amazônica e no ambiente militar, o compartilhamento de metodologias usadas com tendência a propiciar uma visualização mais abrangente. $\mathrm{Na}$ estruturação desta obra foi observada a cronologia de sapiência da função, ou seja, o resumo de ambientação com o contexto apresentado, abordando as congruências e disparidades, posteriormente o entendimento sobre logística, com ênfase na diversidade entre o laudo civil e militar, a apresentação em duas etapas dos resultados, com a utilização de ferramentas da qualidade, especialmente fluxograma e $5 \mathrm{~W} 2 \mathrm{H}$, finalizando com uma conclusão, no embasamento de todo o contexto apresentado e referências de acordo com as obras, recortes, revistas e mapas utilizados na formulação.

O transporte deve receber todas as prioridades necessárias. Seja para movimentar produtos finais, matérias-primas, componentes ou pessoas, ele deve ser rápido, eficiente e barato [4].

Logística: Logística na ótica dos primórdios tempos demonstrou ser parcela significante do sucesso ou fracasso em atividades de emprego militar e posteriormente em gestão de organizações com fins lucrativos. A Logística é originaria da palavra francesa loger, que significa "acomodar" ou "alojar", enquanto que outros autores afirmam que é derivado do grego "logos", que significa "a arte de calcular" ou "a manipulação dos detalhes de uma operação [5]. Como pioneiro de logística podemos citar "Alexandre o grande" que entre suas premissas e virtudes destacava-se sua imensa capacidade de raciocínio lógico que anos após inspirou grandes líderes como Napoleão e Júlio César. Ao assumir o posto de general aos 20 anos, introduziu conceitos de logística contratando equipes de engenheiros para estudar seus adversários antes das batalhas, assim reduzindo a resistência de seus inimigos. Como iniciativa destaca-se também a atuação de contramestres que compravam suprimentos necessários a um exército antes mesmo que esse chegasse àquela localidade. Outra inovação logística foi a criação de uma lança, tornando seus comandados mais rápidos e ágeis. Com toda essa cauda logística o exército macedônico conseguia marchar pelos campos de batalha a velocidades duas vezes maiores que outros exércitos rivais. O conceito significa confiabilidade, contabilidade, organização. A abordagem sobre o planejamento e realização de vários projetos, foi amplamente utilizado durante as grandes guerras, sendo amplamente utilizada como parcela de álgebra e lógica matemática. Por conta de sua importância na cadeia de abastecimento, a logística tem recebido grande atenção nos últimos anos. Bem feito e administrado, esse segmento pode contribuir para reduzir os custos com estocagem, valores de frete, preço final ao consumidor, e outros [6]. O início desta definição, como mencionado acima foi na área militar, o cuidado com o planejamento de itens importantes como: armazenamento, distribuição e manutenção de materiais, armas, roupas, alimentos, saúde, transportes além de posteriormente demandar a gestão, armazenamento e distribuição de recursos para uma determinada atividade.

Modais: São basicamente cinco os modais de transporte de cargas; rodoviário, ferroviário, aquaviário, dutoviário e aéreo. Cada um possui custos e características operacionais próprias, que os tornam mais adequados para certos tipos de operações e produtos. Os critérios para escolha de modais devem sempre levar em consideração aspectos de custos por um lado, e características de serviços por outro. Em geral, quanto maior o desempenho em serviços, maior tende a ser o custo do mesmo [7].

Rodoviário: É o mais expressivo no transporte de cargas no Brasil, atingindo praticamente todos os pontos do território nacional, pois desde a década de 50 com a implantação da indústria automobilística e a pavimentação das rodovias, esse modo se expandiu de tal forma que hoje é o mais procurado[8]. Para [9], assim como para [10], uma das grandes vantagens do transporte rodoviário é o de alcançar praticamente qualquer ponto do território nacional, com exceção de locais muito remotos, os quais, por sua própria natureza, não tem expressão econômica para demandar esse tipo de serviço. $\mathrm{Na}$ transferência de produtos entre a fábrica e um centro de distribuição, seja ele da própria indústria, de um atacadista/distribuidor ou de um varejista, a escolha predominante é o da lotação completa.

Aéreo: O transporte aéreo que é realizado com aeronaves, podendo ser efetivado apenas dentro do país e podendo também envolver ou países, sendo continental ou internacional, os com realização no país é chamado doméstico, nacional ou cabotagem, e o que envolve países estrangeiros é o internacional [11]. A aviação é um modal de transporte essencial para o deslocamento de pessoas e cargas quando se trata de grandes distâncias ou de redução de tempo em viagens [12].

Ferroviário: A ferrovia foi o primeiro meio de transporte moderno utilizado pela economia de mercado como instrumento no seu processo de expansão, ela reduziu o tempo e o espaço entre os povos. Os caminhos de ferro, além de resolverem o problema do transporte e a comunicação da sociedade moderna, impulsionaram a indústria de bens e capital acelerando, assim, a transformação na indústria metalúrgica [13]. O transporte ferroviário de cargas foi relativamente pouco afetado pela crise e, mesmo durante a recessão, apresentou crescimento no volume de cargas transportadas Essa é uma das constatações da Sondagem Expectativas Econômicas do Transportador 2018, realizada pela CNT [14].

Hidroviário: O transporte hidroviário é o mais econômico e menos poluente entre os modais. Em contrapartida, o transporte de cargas urbanas é um desafio hoje. O uso do transporte hidroviário na movimentação urbana de cargas permite redução de custos, melhoria de serviços e redução de impactos ambientais [15]. Sendo assim, investimentos em sistemas de transporte hidroviários integrados a outros modos de transportes devem ajudar a atender a demanda de um 
mercado competitivo, a fim de otimizar os benefícios econômicos, financeiros, ambientais e sociais, uma vez que hidrovias interiores apresentam baixo custo de capital, custo de manutenção mais barato e maior eficiência de combustível, além de apresentarem maior capacidade de movimentação de carga do que os modos de transporte rodoviário e ferroviário[16].

Modal Hidroviário no Amazonas: O estado brasileiro é composto de diversas vias de navegação interior com canais delimitados possuindo 12 grandes bacias hidrográficas, com malha hidroviária de 42 mil km, sendo destes 21 mil km de rios navegáveis e $15 \mathrm{mil} \mathrm{km}$ de trechos potencialmente navegáveis [17]. A hidrografia do Amazonas é a principal via de escoamento da região Norte, é responsável por parcela de $65 \%$ do total transportado. Com extensão de $1.646 \mathrm{~km}$, atravessando as bacias dos rios Foz do Amazonas, Jatapu, Madeira, Negro, Paru, Tapajós, Trombetas e Xingu. Esta hidrovia é continuidade da hidrovia do Solimões que possui $1.630 \mathrm{~km}$ e percorre as bacias dos rios Iça, Japurá, Juruá, Jutaí, Negro e Purus. Ainda parte da hidrovia do Madeira que apresenta extensão navegável de $1.060 \mathrm{~km}$, entre Porto Velho e a foz, em Itacoatiara (AM). Destes, aproximadamente 180 $\mathrm{km}$ estão dentro dos limites de Rondônia e $876 \mathrm{~km}$ no estado do Amazonas. [18].
No conceito de realizar logística na Amazônia, é possível elencar diversos fatores que podem contribuir de maneira negativa para o cenário, dentre eles, o distanciamento entre as cidades e do estado para com o restante dos distribuidores, o isolamento perante os grandes centros produtivos, os meios de transporte empregados de maneira unilateral, a pequena versatilidade de modais. O estado mesmo com as variáveis notáveis que poderiam influenciar no resultado daquilo que é comercializado, galga esforços contínuos para fazer parte da cúpula de líderes em processos de fabricação e escoamento de materiais e serviços. A atuação das forças armadas concomitante com a potencialização obtida através do polo industrial da cidade de Manaus externam a contribuição com os diversos setores para uma remontada da logística no local, desde a aquisição de diversos insumos, meios e recursos humanos, até investimentos em capacidade de ocupação demográfica e logística integrada. A variabilidade climática da região é fator preponderante para a correta utilização das ferramentas que ora se desenvolvem na região, o conceito de obter informações sobre a carta terreno, hidrografia, cartas náuticas, dados de tempestades, fundamentalmente são aprimoradas e a cada atualização contribuem de forma significativa buscando tornar principalmente $o$ modal transporte mais seguro, diminuindo falhas do maquinário e também colaborando com a capacidade laborativa dos recursos

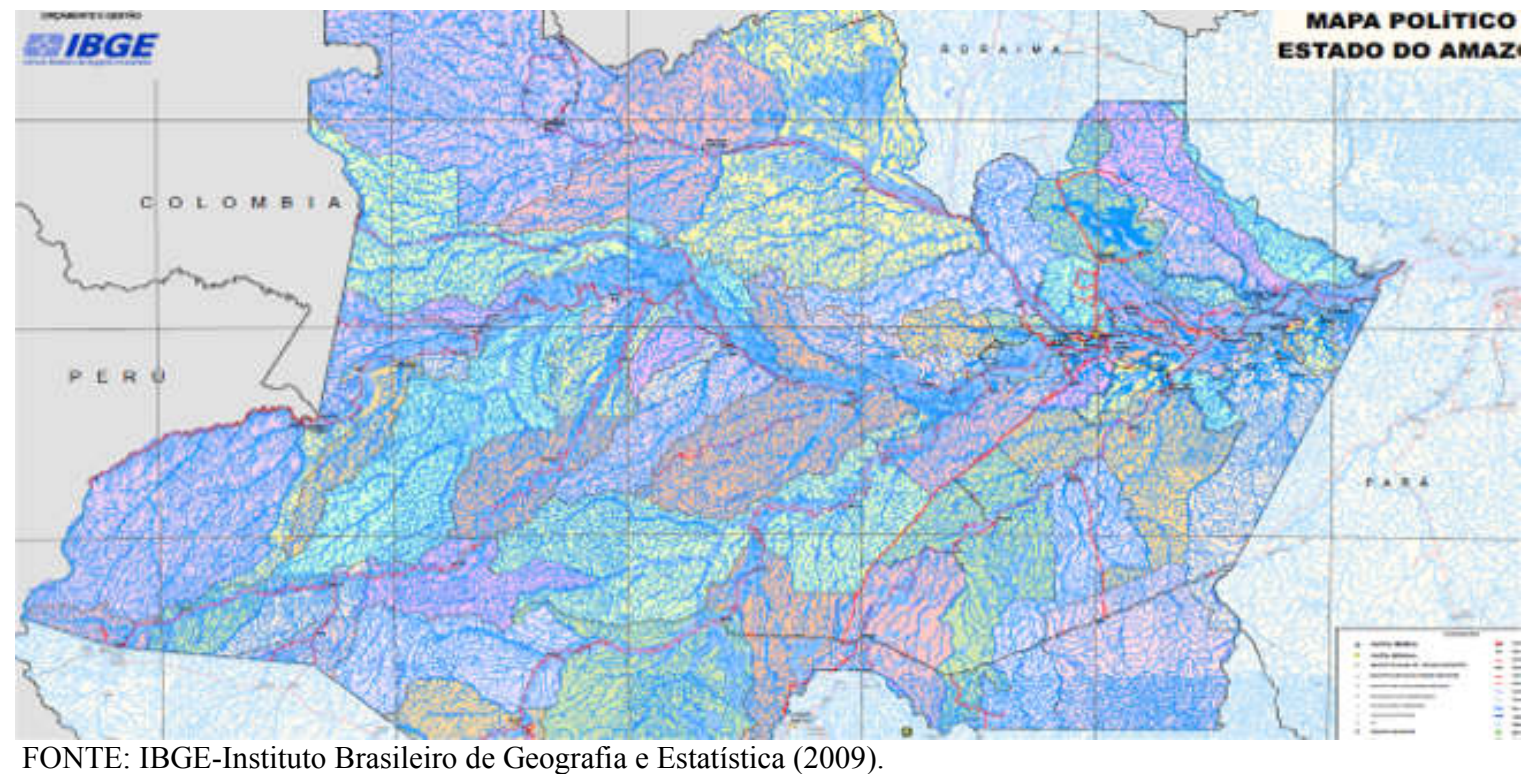

Fig. 1. Hidrovias da Amazônia

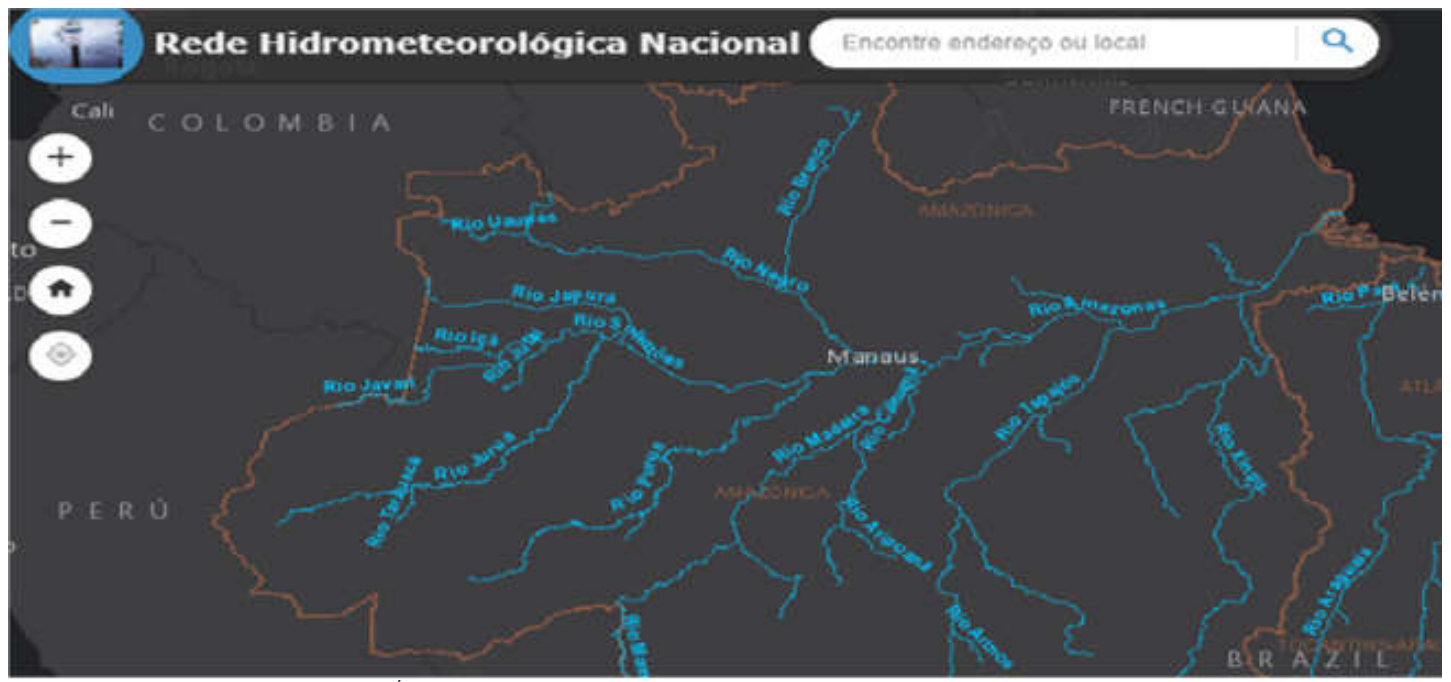

Fonte: ANA- Agência Nacional de Águas (2018).

Fig. 2. Principais hidrovias do estado do Amazonas 
humanos no processo complexo de tomada de decisão para continuidade de apoio. A figura 1 mostra as hidrovias do Amazonas. Na Amazônia as características naturais, marcadas pela presença da floresta equatorial e da bacia hidrográfica do rio Amazonas, influenciam a ocupação humana e $\mathrm{o}$ desenvolvimento das atividades econômicas [19]. Os fatos apresentam a explicação da utilização do meio hidroviário para execução do transporte, assim como os mapas disponíveis em [20] e [21], apresentadosna figura 2, que demonstram a quantidade de rios e principais hidrovias no estado.

Ferramentas da qualidade: As ferramentas da qualidade são meios de identificação e melhoria de diversos processos desenvolvidos para este fim, dentre elas destacam-se:

Histograma: ferramenta gráfica que se própria para verificar a frequência de dados como se distribuem, comumente chamado de Gráfico de Distribuição de Frequências, sua representação é gráfica por barras e a sua visualização auxilia na compreensão de distintos erros;

Diagrama de Pareto: constitui na ferramenta que auxilia na identificação da relação causa e consequência/efeito. Sua análise gráfica verifica os principais problemas que afetam uma organização e seus processos.

Diagrama de Ishikawa: ferramenta utilizada para identificação de causas raízes do problema. O Diagrama Espinha de Peixe é uma alternativa de estudo com profundidade das causas de um efeito negativo, levantando todas as variáveis que influenciaram o resultado não esperado.

Carta de Controle: é gráfica que podendo auxiliar visualmente o acompanhamento de processos e variabilidades. Popular gráfico de controle, servindo na identificação estatística dos desvios e alterações não esperadas que podem ocorrer em determinada etapa de um processo.

Fluxograma de processos: é uma representação gráfica que tem por finalidade descrever o passo a passo e etapas em sequência de um processo. $\mathrm{O}$ fluxograma pode ser útil no nos desenhos dos processos indicando visualmente: o início e fim de um processo; as atividades de um processo: os pontos de decisão; os documentos necessários; o fluxo contínuo de uma informação e outas extrações necessárias ao desenvolvimento. Através de símbolos geométricos convencionados possibilita a compreensão por completo das ligações, identifica-se gargalos e problemas que possam gerar desperdícios e retrabalhos.

Diagrama de Dispersão: é utilizada para identificar a correlação entre variáveis, para quem busca entender se uma relação de causa e efeito, demonstra-se a ferramenta ideal.

Folha de verificação: basicamente é uma lista de itens que foi estabelecida de certificação de condições de um trabalho, produto, processo ou qualquer outra ação. O Checklist, auxilia no ateste das etapas e ou itens da que foram cumpridas conforme o programado.

5W2H: segunda ferramenta utilizada nesta obra caracteriza-se pelas iniciais: O que será feito, Por que será feito, Onde será feito, Quando será feito, Por quem será feito, Como será feito e Quanto custará fazer (custo), tornando esta ferramenta extremamente útil para as empresas, uma vez que elimina por completo qualquer dúvida que possa surgir sobre um processo ou sua atividade. $\mathrm{O} 5 \mathrm{~W} 2 \mathrm{H}$ destaca-se das metodologias de gestão por sendo ferramenta simples, eficiente e completa, com dinâmica, permitindo ajustes e modificações mesmo quando o plano foi colocado em prática.

\section{MATERIAIS E MÉTODOS}

Esta obra baseou-se no estudo de diversos títulos de emprego da logística, seja na arte civil ou no espectro militar. A diversidade do assunto foi de massiva importância para obtenção de dados de modo metodizado nos ambientes em que se desenvolvem as atividades citadas no contexto. A análise dos primórdios da história logística foi o primeiro passo para obtenção de conteúdo, na sequência da segmentação a busca se deu na objetividade em relacionar este assunto com a capacidade efetiva do curso. $O$ arranjo desta obra se desenvolveu no ninho de uma Organização Militar que executa o transporte de gêneros de todas as classes de suprimento aos mais distintos e distantes rincões da área amazônica, propriamente na seção que planeja e controla a realização de missões logísticas que atendem as demandas supracitadas. No intuito de formar conteúdo verídico e enraizado foi necessário recorrer a manuais que regem a logística militar, a programas de operação padrão, a artigos publicados por exemplo integrantes deste centro de coordenação bem como avaliar a massiva experiência dos integrantes atuais deste complexo processo logístico. Na convergência do material coletado, os paradigmas de execução do transporte de artefatos da caserna, evidenciaram a necessidade da miscigenação das estruturas civis e militares para abertura do espectro de evolução da atividade militar observada. A variável direta como a falta de apetite lucrativo da adjacência militar se demonstrou paralelamente proporcional a necessidade de austeridade de recursos, assim como a ínfima necessidade de segurança da adjacência civil é inversamente proporcional a incessante busca de seguridade dos artefatos militares.

Desta forma, o elemento de massiva utilização foi a pesquisa bibliográfica, acompanhado de experiência na área, combinando a ferramentas de qualidade como fluxograma e 5W2H servindo assim de base para realização da contextualização da obra. O método de fluxograma baseando em [22] compreende no mapeamento e melhoria de processos que são métodos utilizados para descomplicar a transição de fluxos, coincidindo com a operacionalização do sequenciamento de ações. O benefício principal se evidencia na maneira simplificada das relações burocráticas com a organização. Dentre as vantagens na utilização do fluxograma, segundo [23] estão: Permissão para verificação da conexão e relacionamento dos componentes de um sistema, mecanizado ou automatizado, propositando a sua eficácia; Localiza deficiências, pela facilidade de visualização dos passos, transportes, operações e ou formulários; Facilita a compreensão das alterações que ocorrem nos sistemas existentes pela visualização das modificações introduzidas. A ferramenta da qualidade 5W2H tem como metodologia uma cadeia de perguntas direcionadas ao processo em estudo no qual permite identificação das rotinas mais importantes, proporcionando a detecção de seus problemas e possíveis soluções. Na presente obra, o método 5W2H se mostrou eficaz para detalhamento de cada parcela componente do processo de planejamento do fluxo logístico militar. As dinâmicas orientadas nas operações de transporte possibilitaram a validação das sugestões para a melhoria de toda a cadeia abordada. 
Aplicação do Estudo: A Política e a Estratégia Nacional de Defesa definiram a Amazônia como prioridade para as ações estratégicas de defesa, a fim de ampliar a capacidade de pronta resposta das forças armadas na Região. Necessita, para isso, de uma infraestrutura de transporte adequada, a ser proporcionada pelos órgãos governamentais responsáveis, em coordenação com o Ministério da Defesa, cumprindo a fase de preparo da logística nacional, prevista na Política Nacional de Mobilização, de forma a facilitar a evolução para uma eventual situação de conflito armado na Região, o que exigiria a mobilização de meios militares [24]. Com base em todos estes dados apresentados, a conclusão de que o modal fluvial é o mais adequado a região é óbvia. Neste contexto, abaixo o Fluxograma [25] demonstra o passo a passo da execução do transporte quando este está na ótica militar e o 5W2H[26] explica seus processos.

Apresentação do fluxograma de decisão do transporte: A seguir na figura 3, é apresentado o fluxograma de decisão de transporte utilizado no estudo. deslocamento, a quantidade de material, o meio de transporte que possui a total capacidade de transportar, a peculiaridade do período do ano, o valor disponibilizado para execução do transporte, e a finalidade para qual será executado, as manobras a serem executadas para possibilitar a utilização daquele eixo;

2- O passo (2) após a definição da execução por modal fluvial, reflete a escolha do módulo logístico, são levados em consideração o item 1 com acréscimo das condições de higidez e psicológica do pessoal que executará a missão, a manutenção do meio de transporte à ser empregado, a condição climática de todo o trajeto a ser trafegado, o local a ser trafegado em relação a segurança do material e do pessoal empregado e a quantidade de carga;

3- O passo (3) consiste na execução propriamente dita do transporte, a arte de movimentar cargas com propósito, no tempo certo, pelo caminho previamente planejado, mantendo suas características físicas,

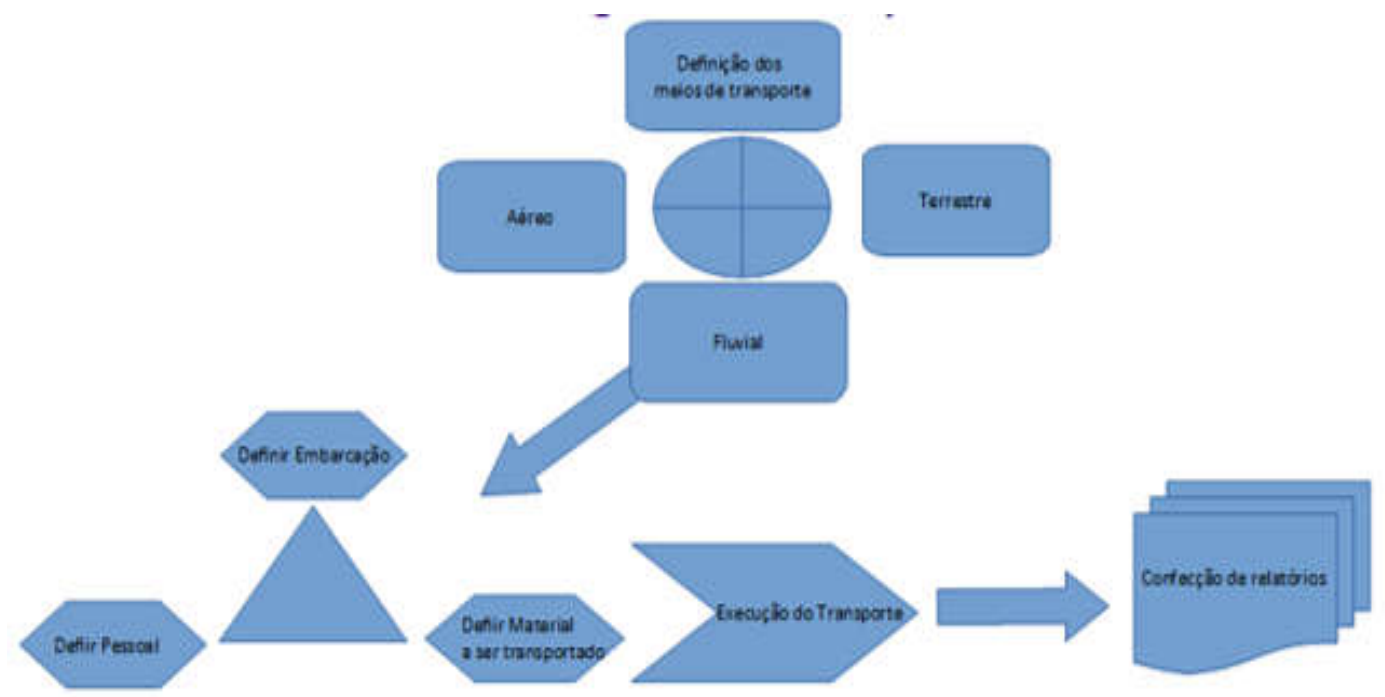

Fonte: Os autores, 2020.

Fig. 3. Fluxograma de Transporte

Tabela 1. Esquematização da execução do transporte logístico

\begin{tabular}{|c|c|c|c|c|c|c|}
\hline Quem & Quando & Onde /Onde & Como & Quem & Quanto & Porque \\
\hline $\begin{array}{l}\text { Definição de } \\
\text { execução Transporte }\end{array}$ & 1 ano antes & $\begin{array}{l}\text { Centro de } \\
\text { Coordenação de } \\
\text { Transporte }\end{array}$ & $\begin{array}{l}\text { Envio de documento } \\
\text { formal aos envolvidos na } \\
\text { atividade. }\end{array}$ & $\begin{array}{l}\text { Chefe do Centro } \\
\text { de Coordenação. }\end{array}$ & - & $\begin{array}{l}\text { Validar } \\
\text { processos de } \\
\text { transporte. }\end{array}$ \\
\hline $\begin{array}{l}\text { Definição } \\
\text { Embarcação }\end{array}$ & 1 mês antes & $\begin{array}{l}\text { Centro de Execução } \\
\text { de Transporte }\end{array}$ & $\begin{array}{l}\text { Verificar melhor } \\
\text { embarcação e trecho }\end{array}$ & Chefe do Centro & $\begin{array}{l}\text { Variável por } \\
\text { manutenção } \\
\text { corretiva }\end{array}$ & $\begin{array}{l}\text { Melhores meios } \\
\text { a disposição }\end{array}$ \\
\hline Definição tripulação & 20 dias antes & $\begin{array}{l}\text { Setor de pessoal do } \\
\text { Centro de Execução }\end{array}$ & $\begin{array}{l}\text { Coordenação de todos os } \\
\text { envolvidos }\end{array}$ & $\begin{array}{l}\text { Chefe do Setor } \\
\text { de Pessoal }\end{array}$ & $\begin{array}{l}\text { Gratificação } \\
\text { de } \\
\text { representação }\end{array}$ & $\begin{array}{l}\text { Pessoal } \\
\text { habilitado a } \\
\text { atividade }\end{array}$ \\
\hline $\begin{array}{l}\text { Material a ser } \\
\text { transportado }\end{array}$ & 15 dias antes & $\begin{array}{l}\text { Realização do } \\
\text { embarque de } \\
\text { materiais }\end{array}$ & $\begin{array}{l}\text { Montagem do croqui de } \\
\text { embarque de materiais }\end{array}$ & $\begin{array}{l}\text { Chefe do Setor } \\
\text { Logístico }\end{array}$ & - & $\begin{array}{l}\text { Coordenar as } \\
\text { operações de } \\
\text { embarque }\end{array}$ \\
\hline Execução Transporte & Partida & $\begin{array}{l}\text { Do local de início até } \\
\text { o destino final }\end{array}$ & $\begin{array}{l}\text { Embarcações, } \\
\text { empurradores e balsa }\end{array}$ & $\begin{array}{l}\text { Selecionados } \\
\text { para realização } \\
\text { do transporte }\end{array}$ & $\begin{array}{l}\text { Suprimentos } \\
\text { para } \\
\text { emergências }\end{array}$ & $\begin{array}{l}\text { Para suprimento } \\
\text { de locais } \\
\text { distantes }\end{array}$ \\
\hline $\begin{array}{l}\text { Confecção dos } \\
\text { relatórios }\end{array}$ & Após a chegada & $\begin{array}{l}\text { Do executor ao } \\
\text { planejador }\end{array}$ & $\begin{array}{l}\text { Através de documento } \\
\text { formal }\end{array}$ & $\begin{array}{l}\text { Executor do } \\
\text { Transporte }\end{array}$ & $\begin{array}{l}\text { Material de } \\
\text { sobra }\end{array}$ & $\begin{array}{l}\text { Documentar os } \\
\text { fatos }\end{array}$ \\
\hline
\end{tabular}

Fonte: Os autores, 2020.

1- O passo número (1) consiste na tomada de decisão sobre qual meio de transporte será executado, os prérequisitos a serem levados em consideração são: o material, sua quantidade, volume, peculiaridades, o local de destino, o tempo estimado para cada entregando-o da melhor forma possível ao destino, proporcionando à aquela localidade uma condição de continuar executar o que lhe foi ordenado;

4- O passo (4) é a parte posterior ao término do transporte, consistindo na confecção dos relatórios de 
missão, a quantidade de horas de motor ligado, a carga transportada, o pessoal empregado, os locais de permanência, o combustível, gêneros alimentícios, kits de manutenção consumidos, as alterações encontradas no pessoal, material transportado, máquinas utilizadas, as oportunidades de melhoria para o próximo trecho, objetivando o histórico da atividade.

Esquematização da execução do transporte logistic: É apresentado o esquema de execução do transporte na tabela 1 . Corroborando com a tabela 1, observa-se os elementos que são imprescindíveis no processo de tomada de decisão durante o transcorrer do planejamento de missões logísticas, cada tópico descrito se configura como etapas para execução do transporte. São eles:

Definição da execução do transporte - Antecedência de 01(um) ano de regulamentação entre o ordenante e o executante através de documentação oficial, para trâmite correto de planejamento e execução correta de cada etapa;

Definição da embarcação - Antecedência de 01(um) mês, levando em consideração todo o lapso de tempo de preparo, alocação de mobília na embarcação, abastecimento dos tanques e principalmente manutenção de todo o módulo, inclusive as balsas;

Definição da tripulação - Antecedência de 20(vinte) dias, consiste em preparação individual de cada militar escolhido, adequação ergonômica do material, planejamento de rotas, planejamento de alocação de cargas;

Material a ser transportado - Antecedência de 15(quinze) dias, momento de preparação, embarque e adequação da carga, levando em consideração as que desembarcarão primeiro e a quantidade de peso distribuído, além da mobilidade dentro dos meios empregados.

Execução do transporte - Consiste no deslocamento de cargas propriamente dito, do destino inicial ao final e viceversa; e

Confecção de relatórios - Os relatórios históricos da operação, embasam as próximas atividades, informações relevantes como horas, trecho percorrido, consumo, material, ocorrências e oportunidades.

\section{RESULTADO E DISCUSSÕES}

Como pode-se perceber, planejar e organizar todos os procedimentos necessários para a execução de forma eficiente e eficaz das ordens de transporte logísticas é um processo complexo e demanda envolvimento de diversos setores e responsáveis. Além disso para que haja um fiel cumprimento daquilo que foi proposto, há a necessidade de fiscalizar o todas as atividades descritas em suas imiscuidades. E possível visualizar as relações espelhadas entre as logísticas militar e civil, possibilitando uma simultaneidade de aprendizado quando comparadas durante a execução de um arranjo. A caracterização das atividades relacionadas procura esclarecer áreas mútuas de atuação e embasar o planejamento e execução de distintas variantes e desafios operacionais. A proposta desta obra é, conforme visto nas análises, e conforme figura 4, pode propiciar as duas áreas que beneficiem da maturidade das Forças Armadas e das aplicações logísticas civis.

\section{Comparativo de anuências entre atividades civis e militares}

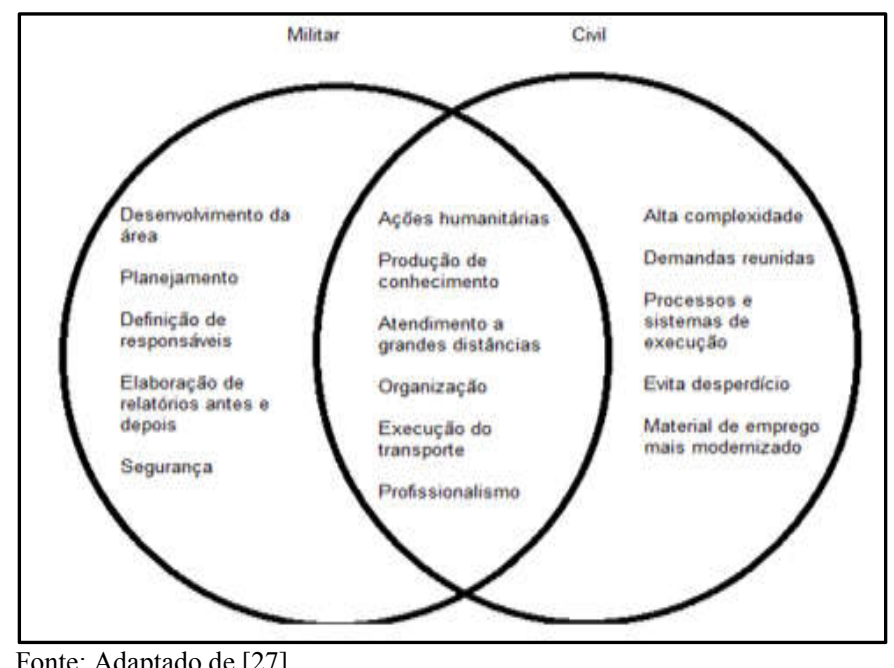

Fonte: Adaptado de [27].

Fig. 4. Congruências de função logística

$\mathrm{Na}$ figura 4, de acordo com todo o material coletado e produzido nesta obra, podemos observar cada área logística que se assemelham nas atividades civis e militares e também dentro deste segmento visualizar cada ponto de igualdade. Portanto:

Militar: Desenvolvimento da Área: Observa-se que a parcela militar desta ambiguidade busca incessantemente galgar maiores conhecimentos na área tratada, para tornar-se especialista na atividade;

Planejamento: Planejar é uma arte milenar bastante empregada em atividades militares e no fluxo de insumos tem bastante demanda e autoridade em decisões em que a envolvem;

Definição de responsáveis: Como base institucional, a hierarquia define cada parcela do todo a executar determinada tarefa em qualquer área de emprego da força;

Elaboração de relatórios antes e depois: A busca pela excelência demanda a produção de conteúdo, demanda indispensável para fortalecimento de teses; e

Segurança: Pela peculiaridade do material transportado, a segurança é parcela primordial do resultado final bemsucedido de cada execução logística.

\section{Entrepostas}

Ações humanitárias: Ações realizadas por ambas instituições que tendem a promover o bem estar do todo;

Produção de conhecimento: Semelhança essa que proporcionou diversos avanços notáveis principalmente no ramo da Engenharia Civil e que inicia seu processo de ramificação na logística de ambos; 
Atendimento a grandes distâncias: A atenção a todo território é missão militar e quando não é suficiente é oportunidade civil;

Organização: Como em qualquer ramo de qualquer instituição, o crescimento somente se dissemina com ordem;

Execução do transporte: A maleabilidade dos meios é uma peculiaridade que ambos segmentos possuem, militarmente pela necessidade da execução, civilmente pela oportunidade lucrativa; e

Profissionalismo: Evitar circunstâncias de instabilidade e executar o previsto em lei são pilares militares, realizar execuções logísticas sem perdas, são crescimento ao civil.

Civil: Alta complexidade: Execuções de demandas exorbitantes, seja em valores ou demandas;

Demandas reunidas: $O$ lucro objetiva levar o máximo possível, assim diminuindo o valor daquilo que está sendo atribuído ao processo;

Processos e sistemas de execução: Conceitos produzidos, mapeados, de confiabilidade e com bastante histórico;

Evita desperdício: Quanto menor o desperdício, maior o ganho, o objetivo é concluído;

Material de emprego modernizado: Pela quantidade de demanda e objetivo final, a quantidade de atualizações sistemáticas e de meios é considerada necessária a todos os períodos.

\section{Considerações Finais}

Como evidenciado, as características peculiares da região longínqua, combinadas a um elevado grau de disparidade do material a ser transportado, elucidam cumes distintos no processo de planejamento e consequentemente na execução propriamente dita da função logística, tornando objetiva a descrição dos procedimentos realizados na logística do modal fluvial militar nos rincões amazônicos. A grande valia da obra é a apresentação de etapas, cujo extrato contribuirá com a formatação das futuras delineações no ramo, ornamentando um cenário mais produtivo e de maior eficácia, tendo em vista a situação de dependência da região. A cauda desta ciência assemelha parcela de seus objetivos quando defronta em duas vertentes, a civil e a militar. Os pontos ápices de uma logística na caserna, emolduram suas pilastras nas variantes do saber "conceitos de estratégia", querer "força de vontade" e poder "capacidade operativa", inversamente, no ambiente empresarial onde o cume mais forte está intimamente ligado ao saber, pois geram reações de lucratividade e status no capital humano. A elaboração de material bibliográfico do tema tornase plausível, à medida que se observa a existência de poucas e contáveis referências sobre a temática, tornando por vezes o campo de tomada de decisões empírico e resultam em problemáticas de solução de continuidade, ou seja, o grande conhecimento acerca do assunto na sabedoria de poucos. Embasado no campo de pesquisa o conteúdo produzido tem como resultante a figura 4 de congruências dos meios civil e militar perante a logística e mais especificamente da função transporte hidroviário na região amazônica, a anuência da necessidade de modernização estrutural da metodologia militar se torna evidente, ou seja, a produção desta obra formula um ponto inicial de análise para evolução de ambas diretrizes.

Agradecimentos: Agradeço ao Centro Universitário Fametro, ao professor-orientador e a família.

\section{REFERÊNCIAS}

DE CARVALHO, JOSÉ MEXIA CRESPO, EDUARDO GOMES CARDOSO. Logística. Sílabo, 2002.

MINISTÉRIO DA DEFESA EXÉRCITO BRASILEIRO ESTADO-MAIOR DO EXÉRCITO. Manual DE Campanha Logistica Militar Terrestre. EB70-MC-10.238 $1^{\mathrm{a}}$ Edição.2018

SANTOS, JOSÉ TEIXEIRA DE ARAÚJO NETO. Modelo Logístico Hidroviário. 2017. 81 f. Dissertação (Mestrado em Engenharia de Produção) - Universidade Federal do Amazonas,Manaus,2017.

Disponível em:<http://200.129.163.131:8080/handle/tede/5916\#previ ew-link0 >. Acesso em: 03 de set 2019 15h.

BERTAGLIA, PAULO ROBERTO. LOGÍSTICA E GERENCIAMENTO DA CADEIA DE ABASTECIMENTO. EDITORA SARAIVA, 2017.

JOURNET, M. Evolution de la LogistiquedesEntreprisesIndustrielles et Commerciales. In: RevueAnnuelle 98 des Eleves desArts et Métiers. Logistique: Maitrisedes Flux. Paris: Ed. Dunod, 1998.

SILVA, Ana Rosa Cavalcanti da. Tipos de Transporte (Modais). Recife: SEDUC, 2013. Apostila.

ORNELlAS, A., \& de Campos, R. (2008). Características de modais de transporte e requisitos para simulações na área de logística.Revista GEPROS,3(3), 69.

RIBEIRO, Priscilla Cristina Cabral, and Karine Araújo Ferreira. "Logística e transportes: uma discussão sobre os modais de transporte e o panorama brasileiro."XXII Encontro Nacional de Engenharia de Produção23 (2002).

NOVAES, A.G. Logística e gerenciamento da cadeia de distribuição: Estratégia, operação e avaliação. $2^{a}$. Ed. Rio de Janeiro: Elsevier, 2004.

JACOBS, F. R. e CHASE, R. B. Administração de operações e da cadeia de suprimentos. 13 e.d. Porto Alegre: AMGH, 2012.

KUDI, S. Transporte: utilização e seguros internacionais de carga: prática e exercícios. 3. ed. São Paulo: Lex, 2005.

FREIRE, L. L. A.; NASCIMENTO, D. M. Panorama do ambiente regulatório do uso de biocombustível para aviação no Brasil. Programa de Pós-Graduação em Transportes. Universidade de Brasília - UnB, 2015 Brasília - DF, Brasil.

Borges, Barsanufo Gomides. "Ferrovia e modernidade."Revista UFG13.11 (2011).

CNT - CONFEDERAÇÃO NACIONAL DO TRANSPORTE. Pesquisa de Ferrovias, 2019. Dados gerais. Disponível em: Acesso em 18 de novembro de 2019.

RODRIGUES, Ester Divieso Roman, and Orlando Fontes Lima Júnior. "O USO DA HIDROVIA NA LOGÍSTICA URBANA."1 STPR-Simpósio de Transportes do Paraná. 2019.

SARKAR, P.; MATHUR, V.; MAITRI, V.; KALRA, K. Potential for Economic Gains from Inland Water Transport in India. JournaloftheTransportationResearch Board, v. 2033, n. 2033, p. 45-52, 2007.

CAVALCANTE MOREIRA, André.HIDROVIA DO AMAZONAS. DNIT 27 de dezembro de 2018. Disponível 
em: $\quad<$ http://www.dnit.gov.br/modais-2/aquaviario/ hidrovia-do-amazonas $>$ Acesso em 10 set.2019 19h.

HIDROGRAFIA DO AMAZONAS. Página inicial. Disponível em: <https://biblioteca.ibge.gov.br/index.php/ biblioteca-catalogo view $=$ detalhes $\& i d=287871>$ Acesso em: 12 set.2019 17h

SAMPAIO, F. S; MEDEIROS, M. C. Para viver juntos: geografia. 4. ed. São Paulo: Edições SM, 2015.

MAPA POLITICO DO ESTADO DO AMAZONAS. Pagina inicial. Disponível em: $<$ http://www.terrabrasilis.org.br/ ecotecadigital/index.php?option $=$ com_abook\&view $=$ book \&id=587:mapa-Politico $>$ Acesso em : 11 de set.2019 22h.

REDE HIDROMETROLÓGICA NACIONAL. Página inicial. Disponivel em: $<$ http://earthobservatory.nasa.gov/Newsroom/NewIma ges/Images/amazon_srtm_2000_lrg.jpg > Acesso em: 15 set.2019 23h.

AZEVEDO, Irene Conceição Gouvêa. "Fluxograma como ferramenta de mapeamento de processo no controle de qualidade de uma indústria de confecção." Congresso Nacional de Excelência em Gestão. Vol. 12. 2016.
MELLO, A. E. N. S. Aplicação do mapeamento de processos e da simulação no desenvolvimento de projetos de processos produtivos. 2008. 116 f. Dissertação (Mestrado em Engenharia de Produção) - Universidade Federal de Itajubá, Itajubá 2008 Disponível em Acesso em: 05 Nov 2015

MENEZES, CLÁUDIO JOSE DOS SANTOS.As restrições dos modais de transportes rodoviário e hidroviário e seus reflexos para a mobilização de meios na área do Comando Militar da Amazônia." (2018).

ADAPTADO DE LOGÍSTICA MILITAR X LOGÍSTICA HUMANITÁRIA: CONCEITOS, RELAÇÕES E OPERAÇÕES DAS FORÇAS ARMADAS BRASILEIRAS. Universidade Federal de Santa Catarina. Disponivel em: $<$ http://www.anpet.org.br/ssat/interface/content/autor/trab alhos/publicacao/2013/91_AC.pdf >. Acesso em 22 de ago.2019 16h. 